\title{
Design and Fabrication of a Novel T-Shaped Piezoelectric ZnO Cantilever Sensor
}

\author{
Kai Yang, Zhigang Li, and Dapeng Chen \\ Institute of Microelectronics, Chinese Academy of Sciences (IMECAS), Beijing 100029, China \\ Correspondence should be addressed to Kai Yang, kai.yang@utah.edu \\ Received 5 March 2012; Revised 12 May 2012; Accepted 15 May 2012 \\ Academic Editor: Ching Liang Dai
}

Copyright () 2012 Kai Yang et al. This is an open access article distributed under the Creative Commons Attribution License, which permits unrestricted use, distribution, and reproduction in any medium, provided the original work is properly cited.

A novel T-shaped piezoelectric $\mathrm{ZnO}$ cantilever sensor for chem/bio-detection is designed and fabricated with MEMS technology. By using Rayleigh-Ritz method, the fundamental resonant frequency formula of T-shaped cantilevers is deduced for the first time and is validated by simulation results and experimental results. From this formula, we can easily find the superiority of adopting T-shape for the cantilevers. The complete process of the cantilever sensor is then successfully developed. The cantilever sensor is actuated by a layer of high-quality $\mathrm{ZnO}$ film with preferred (002) orientation, which is evaluated by SEM and XRD. The key step of the process is protecting the $\mathrm{ZnO}$ film from $\mathrm{KOH}$ etching by a novel and effective method, which has rarely appeared in the literature. Finally, this cantilever sensor is measured by a network analyzer, and it has a fundamental resonant frequency of $24.60 \mathrm{kHz}$. The cantilever sensor developed in this study illustrates the feasibility and potential for many miniaturized sensor applications.

\section{Introduction}

There is a dramatic and urgent demand to develop inexpensive, microfabricated, and extremely sensitive sensors for chem/bio-sensing. As mass sensitive sensors, microcantilever sensors have many advantages over other transducers. For example, these sensors have been shown to exhibit over two orders of magnitude greater absolute sensitivity such as quartz crystal microbalance (QCM), surface acoustic wave (SAW) devices, acoustic plate mode (APM) devices, chemiresistors, and flexural plate wave (FPW) oscillators [1]. So far, one of the most common ways to detect frequency shift or static deflection of cantilever-based sensors is optical inspection by means of a laser and position sensitive diode (PSD). However, laser and PSD are quite complex and bulky and almost impossible to minimize.

Another popular method without huge optical systems is by using piezoresistive layer on the cantilever itself. Any changes in the surface stress due to bending will cause an electrical output from the piezoresistive electrodes. The disadvantage of piezoresistive technique is that it requires passing a current through the cantilever for displacement measurements. This results in electronic noises and thermal drift in cantilever deflection.

In this study, we choose piezoelectric method for the purpose of simplifying and minimizing the sensors. To date, lead zirconate titanate (PZT) is one of the most widely exploited and extensively used piezoelectric materials. For example, Lee et al. [2] developed a PZT microcantilever biosensor for using in a lab-on-chip (LOC). However, there are a few unsolvable problems for PZT thin films: (1) the crystallization temperature of PZT is in the range of 600 $700^{\circ} \mathrm{C}$, which is not compatible with the CMOS integration [3] (2) a high electric field for poling is necessary, which may be difficult for PZT thin films that have some defects or pinholes [3] (3) the performance is gradually deteriorative due to aging effect [3] (4) PZT is highly toxic, and its toxicity is further enhanced due to its volatilization at high temperature particularly during calcination and sintering, causing environmental pollution [4].

Recently, $\mathrm{ZnO}$ has attracted a lot of attention because it is one of the pollution-free piezoelectric materials which do not suffer from the mentioned problems of PZT. $\mathrm{ZnO}$ finds applications in MEMS due to its unique combination of 
electrical, optical, and piezoelectric properties [5]. However, a serious problem which hinders its MEMS application is that $\mathrm{ZnO}$ is an amphoteric oxide which reacts with both strong acid and strong alkaline and cannot resist $\mathrm{KOH}$ etching. Prior to our research, lack of effective protection and safety methods was a dominating obstacle surrounding the use of this functional material. In fact, few reports presented cantilever sensors with $\mathrm{ZnO}$ and the protection methods. For example, Zhou et al. [6] theoretically designed and simulated a piezoelectric $\mathrm{ZnO}$ microcantilever chemical sensor, but they did not put it into practice. Itoh and Suga [7] successfully micromachined a force-sensing microcantilever with $\mathrm{ZnO}$ layers; however, they did not reveal the protection means in the $\mathrm{KOH}$ etching. Sudhir and Atul [8] have developed a physical protection method using mechanical jig, however this method is quite complex and needs many parts such as screw, plate, pipe, nut, Teflon, silicone O-ring, and neoprene gasket.

Fortunately, we have developed a novel, simple, and practical method to protect the $\mathrm{ZnO}$ film from alkaline etching with a protective coating of black wax (Apiezon-W). Hence, the selected piezoelectric layer in this study is a c-axisoriented $\mathrm{ZnO}$ film.

The sensitivity of resonant microcantilever sensors is directly proportional to the resonant frequency [9]. The resonant frequency is a key parameter to design a sensor with a good sensitivity. Therefore, we put forward a simple and accurate formula to calculate the fundamental resonant frequency of T-shaped cantilevers using Rayleigh-Ritz method. We find that T-shaped cantilevers are superior to rectangular cantilevers, because with the same dimensions and same materials, T-shaped cantilevers can lead to higher fundamental resonant frequency and higher sensitivity. We are the first to report this useful formula, and we also validate the formula by simulation results and experimental results.

As shown in Figure 1, we have designed a novel piezoelectric $\mathrm{ZnO}$ cantilever sensor with a T-shaped geometry in order to enhance the fundamental resonant frequency and the sensitivity. The length and width of the cantilever beam are $288 \mu \mathrm{m}$ and $108 \mu \mathrm{m}$. Besides, the dimensions of the cantilever extension are $96 \mu \mathrm{m}$ long and $36 \mu \mathrm{m}$ wide. The thicknesses of $\mathrm{Si}_{3} \mathrm{~N}_{4}$ and $\mathrm{ZnO}$ film are $0.5 \mu \mathrm{m}$ and $2 \mu \mathrm{m}$, respectively. The frequency characterization of the cantilever sensor has been accomplished by measuring the $S_{12}$ parameter using a network analyzer (Agilent E5100A).

\section{Theoretical Analysis}

2.1. Deflection Function of Rectangular Cantilevers. Figure 2 shows the structure of a single-layered or multilayered rectangular cantilever with length $L$, width $W$, equivalent thickness $H$, equivalent density $\rho$, and equivalent Young's modulus $E$.

When applying a normal force $F$ at the free end of the cantilever, the second-order differential equation of the cantilever can be expressed as [10]

$$
\frac{d^{2} z(x)}{d x^{2}}=\frac{F(L-x)}{E I}=\frac{12 F(L-x)}{E W H^{3}},
$$

where $x$ is the distance from the fixed end, and $I=W H^{3} / 12$ is the cross-sectional area moment of inertia.

As one end of the cantilever is fixed, the corresponding boundary conditions are

$$
\begin{gathered}
z(0)=0 \\
\left.\frac{d z(x)}{d x}\right|_{x=0}=0 .
\end{gathered}
$$

The solution of (1)-(3) can be expressed as

$$
z(x)=\frac{2 F x^{2}(3 L-x)}{E W H^{3}}=A x^{2}(3 L-x) .
$$

This is the deflection function along the length direction, where $A$ is a constant.

2.2. Fundamental Resonant Frequency of T-Shaped Cantilevers. In this section, we derive the fundamental resonant frequency of T-shaped cantilevers using Rayleigh-Ritz method.

Figure 3 shows a typical T-shaped cantilever, whose dimension is defined by five parameters: $L_{0}, L_{1}, W_{0}, W_{1}$, and $H$. Obviously, the width function $W(x)$ of the T-shaped cantilever is a piecewise function that can be written as

$$
W(x)= \begin{cases}W_{1}, & x \in\left[0, L_{0}\right] \\ W_{0}, & x \in\left[L_{0}, L_{1}\right] .\end{cases}
$$

The deflection function of (4) can be used as the mode shape, and the vibration displacement at each position can be written as

$$
z(x, t)=A x^{2}\left(3 L_{1}-x\right) \sin (2 \pi f t+\alpha),
$$

where $A$ and $\alpha$ are constants, $t$ is the time, and $f$ is the frequency.

The kinetic energy of the system is

$$
\begin{aligned}
T & =\int_{0}^{L_{1}} \frac{1}{2}[\rho H W(x) d x]\left(\frac{\partial z}{\partial t}\right)^{2} \\
& =2 \pi^{2} f^{2} A^{2} \rho H \cos ^{2}(2 \pi f t+\alpha) \int_{0}^{L_{1}} W(x) x^{4}\left(3 L_{1}-x\right)^{2} d x
\end{aligned}
$$

Therefore, the maximum kinetic energy of the system is

$$
T_{\max }=2 \pi^{2} f^{2} A^{2} \rho H \int_{0}^{L_{1}} W(x) x^{4}\left(3 L_{1}-x\right)^{2} d x .
$$




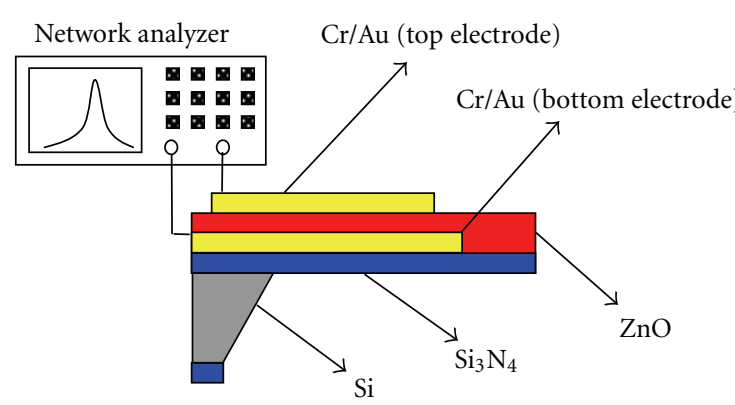

(a) Slide view

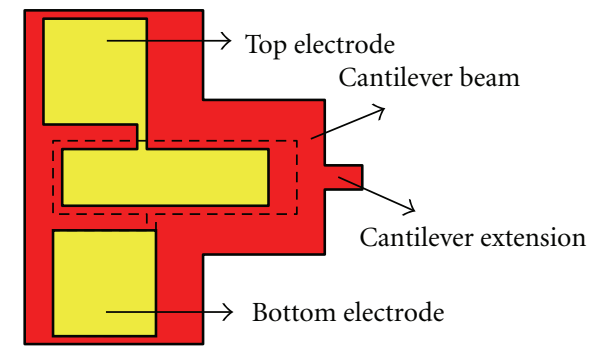

(b) Top view

FIgURE 1: Schematic drawing of the sensor.

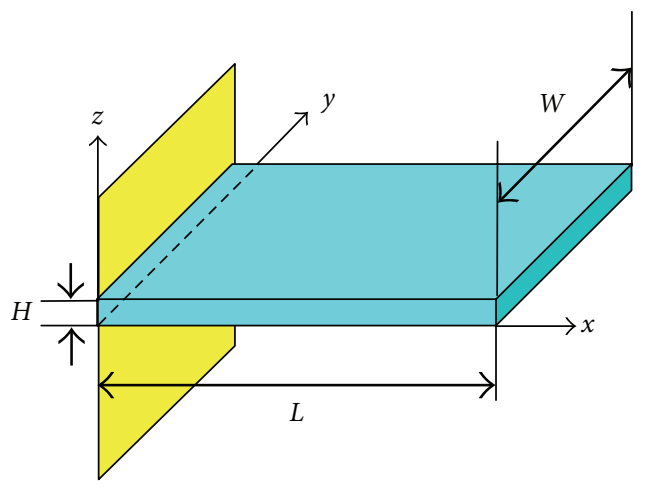

FIGURE 2: Schematic drawing of a rectangular cantilever.

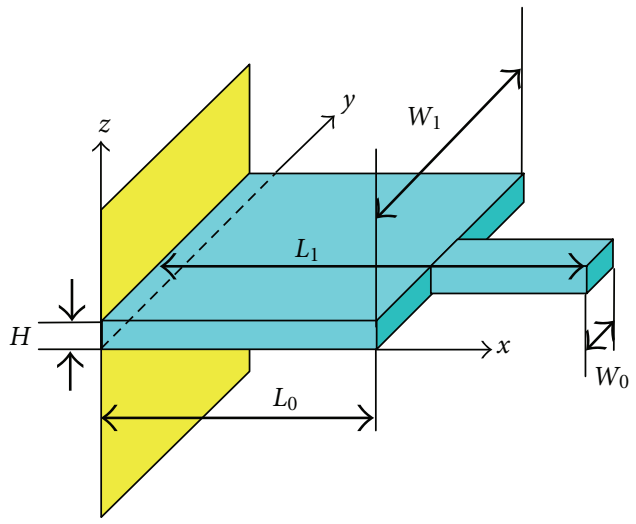

Figure 3: Schematic drawing of a T-shaped cantilever.
The potential energy of the system is

$$
\begin{aligned}
V & =\int_{0}^{L_{1}} \frac{1}{2} E I(x)\left(\frac{\partial^{2} z}{\partial x^{2}}\right)^{2} d x \\
& =\frac{3}{2} E H^{3} A^{2} \sin ^{2}(2 \pi f t+\alpha) \int_{0}^{L_{1}} W(x)\left(L_{1}-x\right)^{2} d x,
\end{aligned}
$$

where $I(x)=W(x) H^{3} / 12$ is the cross-sectional area moment of inertia. is

Therefore, the maximum potential energy of the system

$$
V_{\max }=\frac{3}{2} E H^{3} A^{2} \int_{0}^{L_{1}} W(x)\left(L_{1}-x\right)^{2} d x .
$$

According to conservation law of mechanical energy, the maximum kinetic energy equals to the maximum potential energy:

$$
T_{\max }=V_{\max }
$$

For calculation convenience, it is reasonable to define the width ratio $p$ and the length ratio $q$, both of which range from 0 to 1 :

$$
p=\frac{W_{0}}{W_{1}}, \quad q=\frac{L_{0}}{L_{1}} \quad(p \in[0,1], q \in[0,1]) .
$$

Hence, the fundamental resonant frequency can be obtained by substituting (8), (10), and (12) into (11):

$$
\begin{aligned}
f & =\sqrt{\frac{\left(3 E H^{3} / 4 \pi^{2}\right) \int_{0}^{L_{1}} W(x)\left(L_{1}-x\right)^{2} d x}{\rho H \int_{0}^{L_{1}} W(x) x^{4}\left(3 L_{1}-x\right)^{2} d x}} \\
& =\sqrt{\frac{35 E}{\rho} \frac{H}{2 \pi} \sqrt{\frac{W_{1} L_{0}^{3}-3 L_{1} W_{1} L_{0}^{2}+3 L_{1}^{2} W_{1} L_{0}+W_{0} L_{1}^{3}-W_{0} L_{0}^{3}+3 L_{1} W_{0} L_{0}^{2}-3 L_{1}^{2} W_{0} L_{0}}{5 W_{1} W_{1} L_{0}^{6}+63 L_{1}^{2} W_{1} L_{0}^{5}+33 W_{0} L_{1}^{7}-5 W_{0} L_{0}^{7}+35 L_{1} W_{0} L_{0}^{6}-63 L_{1}^{2} W_{0} L_{0}^{5}}}} \\
& =\sqrt{\frac{35 E}{\rho}} \frac{H}{2 \pi L_{1}^{2}} \sqrt{\frac{q^{3}-3 q^{2}+3 q+p-p q^{3}+3 p q^{2}-3 p q}{5 q^{7}-35 q^{6}+63 q^{5}+33 p-5 p q^{7}+35 p q^{6}-63 p q^{5}}} .
\end{aligned}
$$




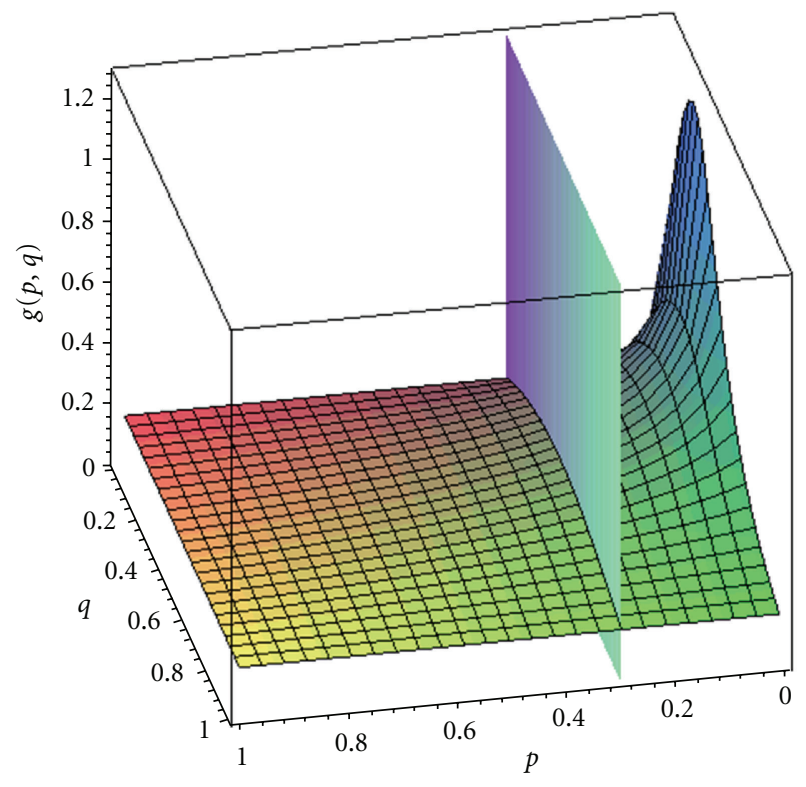

Figure 4: The function image of $g(p, q)$.

In order to represent the relationship between the fundamental resonant frequency and the two ratios $p$ and $q$, we can define a dimensionless characteristic function:

$$
g(p, q)=\sqrt{\frac{q^{3}-3 q^{2}+3 q+p-p q^{3}+3 p q^{2}-3 p q}{5 q^{7}-35 q^{6}+63 q^{5}+33 p-5 p q^{7}+35 p q^{6}-63 p q^{5}}} .
$$

Thus, the fundamental resonant frequency of T-shaped cantilever sensor can be written as

$$
f=\sqrt{\frac{35 E}{\rho}} \frac{H}{2 \pi L_{1}^{2}} g(p, q) .
$$

Figure 4 is the function image of $g(p, q) \cdot g(p, q)>g(1, q)$ shows that, comparing to a rectangular cantilever with same dimensions and same materials, T-shaped cantilevers can always lead to higher fundamental resonant frequency and higher sensitivity. We also find that, when $p$ is fixed, the maximum value of $g(p, q)$ can be obtained when $q$ reaches a proper value between 0 and 1 .

Consider an n-layered T-shaped cantilever of density $\rho_{i}$, Young's modulus $E_{i}$, and thickness $H_{i}$ for $i$ th $(i=$ $1,2,3, \ldots, n$ ) layer, as shown in Figure 5. We put forward an equivalent model method in which the three equivalent physical quantities are defined as follows.

Equivalent density:

$$
\rho_{\mathrm{equ}}=\frac{\sum_{i=1}^{n} \rho_{i} H_{i}}{\sum_{i=1}^{n} H_{i}}
$$

Equivalent Young's modulus:

$$
E_{\mathrm{equ}}=\frac{\sum_{i=1}^{n} E_{i} H_{i}}{\sum_{i=1}^{n} H_{i}}
$$

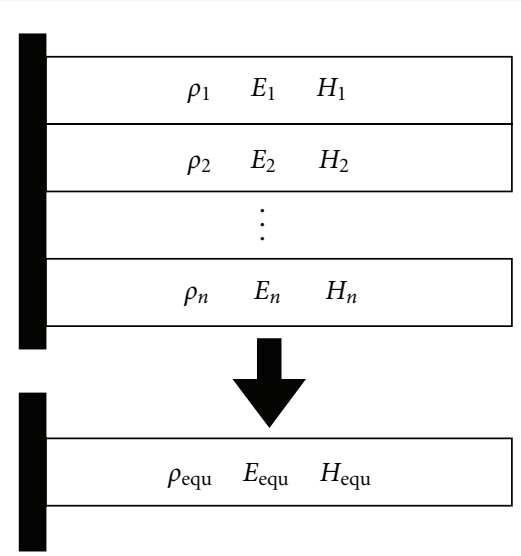

Figure 5: An n-layered T-shaped cantilever and its equivalent monolayered $\mathrm{T}$-shaped cantilever.

Equivalent thickness:

$$
H_{\mathrm{equ}}=\sum_{i=1}^{n} H_{i}
$$

With (16)-(18), the n-layered T-shaped cantilever can be treated as an equivalent monolayered T-shaped cantilever, whose fundamental resonant frequency is simply calculated by substituting these three equivalent parameters into (15) to get

$$
\begin{aligned}
f & =\sqrt{\frac{35 E_{\mathrm{equ}}}{\rho_{\mathrm{equ}}} \frac{H_{\mathrm{equ}}}{2 \pi L_{1}^{2}}} g(p, q) \\
& =\sqrt{\frac{35 \sum_{i=1}^{n} E_{i} H_{i}}{\sum_{i=1}^{n} \rho_{i} H_{i}}} \frac{\sum_{i=1}^{n} H_{i}}{2 \pi L_{1}^{2}} g(p, q) .
\end{aligned}
$$

In order to validate (19), we have designed and fabricated a T-shaped piezoelectric $\mathrm{ZnO}$ cantilever sensor as shown in Figure 1. The cantilever sensor has a zinc oxide $(\mathrm{ZnO})$ piezoelectric thin film between two $\mathrm{Cr} / \mathrm{Au}$ layers on a supporting layer of $\mathrm{Si}_{3} \mathrm{~N}_{4}$. The length and width of the cantilever beam are $288 \mu \mathrm{m}$ and $108 \mu \mathrm{m}$. Besides, the dimensions of the cantilever extension are $96 \mu \mathrm{m}$ long and $36 \mu \mathrm{m}$ wide. The thicknesses of $\mathrm{Si}_{3} \mathrm{~N}_{4}$ and $\mathrm{ZnO}$ film are $0.5 \mu \mathrm{m}$ and $2 \mu \mathrm{m}$, respectively. The $\mathrm{Cr} / \mathrm{Au}$ layers of $10 \mathrm{~nm} / 50 \mathrm{~nm}$ are evaporated as the bottom electrode and top electrode. As the thicknesses of $\mathrm{Cr} / \mathrm{Au}$ layers are much smaller than those of $\mathrm{Si}_{3} \mathrm{~N}_{4}$ and $\mathrm{ZnO}$ film, the $\mathrm{Cr} / \mathrm{Au}$ layers can be neglected when calculating the resonant frequency. Hence, the T-shaped piezoelectric $\mathrm{ZnO}$ cantilever can be treated as a double-layered T-shaped cantilever whose geometric and material data of each layer are given in Table 1. 
TABLE 1: Geometric and material data of the T-shaped piezoelectric $\mathrm{ZnO}$ cantilever.

\begin{tabular}{lccc}
\hline Layer & $\begin{array}{c}\text { Density } \\
\left(\mathrm{Kg} / \mathrm{m}^{3}\right)\end{array}$ & $\begin{array}{c}\text { Young's modulus } \\
(\mathrm{GPa})\end{array}$ & $\begin{array}{c}\text { Thickness } \\
(\mu \mathrm{m})\end{array}$ \\
\hline $\mathrm{ZnO}$ & $5676[10]$ & $209.7[10]$ & 2 \\
$\mathrm{Si}_{3} \mathrm{~N}_{4}$ & $3170[10]$ & $270[10]$ & 0.5 \\
\hline
\end{tabular}

Hence, the necessary parameters are listed below:

$$
\begin{gathered}
\rho_{1}=5676 \mathrm{Kg} / \mathrm{m}^{3}, \\
\rho_{2}=3170 \mathrm{Kg} / \mathrm{m}^{3}, \\
E_{1}=209.7 \mathrm{GPa}, \\
E_{2}=270 \mathrm{GPa}, \\
H_{1}=2 \mu \mathrm{m}, \\
H_{2}=0.5 \mu \mathrm{m}, \\
L_{0}=288 \mu \mathrm{m}, \\
L_{1}=288+96=384 \mu \mathrm{m}, \\
W_{0}=36 \mu \mathrm{m}, \\
W_{1}=108 \mu \mathrm{m}, \\
p=\frac{W_{0}}{W_{1}}=\frac{1}{3}, \\
q=\frac{L_{0}}{L_{1}}=\frac{3}{4} .
\end{gathered}
$$

Substituting these parameters into (19), we get $f=$ $25.02 \mathrm{kHz}$.

In order to assess the accuracy of (19), relative error $\delta$ is introduced to compare the calculation results with the corresponding experimental results or simulation results:

$$
\delta=\frac{f-f^{\prime}}{f^{\prime}}
$$

where $f$ refers to the result obtained by (19), and $f^{\prime}$ refers to the resonant frequency obtained by experiments or simulations.

According to experimental results discussed in Section 4, the resonant frequency of this device is $f^{\prime}=24.60 \mathrm{kHz}$. Hence the relative error is

$$
\delta=\frac{25.02 \mathrm{kHz}-24.60 \mathrm{kHz}}{24.60 \mathrm{kHz}}=1.71 \% .
$$

On the other hand, according to the finite-element method (FEM) simulation results, the resonant frequency of this device is $f^{\prime}=24.95 \mathrm{kHz}$. The deformed shape of the first vibration mode is plotted in Figure 6. Hence the relative error is

$$
\delta=\frac{25.02 \mathrm{kHz}-24.95 \mathrm{kHz}}{24.95 \mathrm{kHz}}=0.28 \%
$$

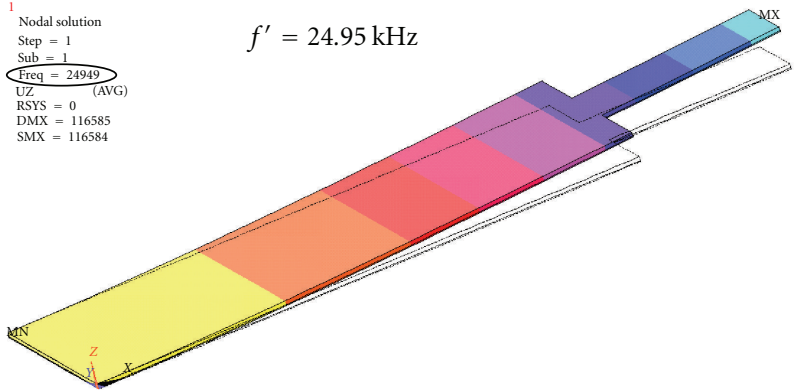

FIgure 6: Deformed shape of the first vibration mode.

It can be noted from these statistics that the relative error is very small, and the formula we have deduced is reasonably accurate.

\section{Fabrication Process}

The piezoelectric $\mathrm{ZnO}$ cantilever sensor is fabricated by MEMS technique depicted in Figure 7. (a) Silicon with (100) orientation is used as a substrate, and $0.5 \mu \mathrm{m}$ thick $\mathrm{Si}_{3} \mathrm{~N}_{4}$ is deposited by LPCVD on both sides of a $510 \mu \mathrm{m}$ thick silicon wafer. (b) The $\mathrm{Si}_{3} \mathrm{~N}_{4}$ layers on front side and back side are respectively etched by RIE to form the cantilever shapes and the $\mathrm{KOH}$ etching windows. (c) $\mathrm{An} \mathrm{Cr} / \mathrm{Au}$ layer of $10 \mathrm{~nm} / 50 \mathrm{~nm}$ used as bottom electrode is evaporated and patterned by lift off. (d) A $2 \mu \mathrm{m}$ thick piezoelectric $\mathrm{ZnO}$ film is deposited by RF magnetron sputtering at $200^{\circ} \mathrm{C}$, using a $99.999 \%$ pure $\mathrm{Zn}$ target. The sputtering gas is a mixture of $37.5 \% \mathrm{Ar}$ and $62.5 \% \mathrm{O}_{2}$ at a pressure of $3 \times 10^{-4} \mathrm{~Pa}$. (e) Another $\mathrm{Cr} / \mathrm{Au}$ layer of $10 \mathrm{~nm} / 50 \mathrm{~nm}$ used as top electrode is evaporated and patterned by lift off. Then, the $\mathrm{ZnO}$ film covering the bottom electrode is etched by dipping with hydrochloric acid. (f) The top of the device is protected by a thick coat of black wax (Apiezon-W), which can resist $\mathrm{KOH}$ etching. (g) The silicon is etched using $33 \mathrm{wt} . \% \mathrm{KOH}$ solution at $75^{\circ} \mathrm{C}$, below $80^{\circ} \mathrm{C}$ which is the softening point of Apiezon-W. (h) The Apiezon-W layer is finally removed by immerging into 1,1,1-trichloroethane.

It is important to emphasize the difficulty for MEMS researchers to find a way to protect electric circuits and other delicate devices during deep silicon wet-etch processes. The challenge exists in choosing an appropriate protective coating that could meet these criteria: (1) easy to cover and remove, (2) having superior adhesion to the substrate without destroying the delicate devices below, (3) being able to persist $\mathrm{KOH}$ etchant for enough time. After testing a great many kinds of protective coatings, such as $\mathrm{Cu}$ and Crystalbond 509, we conclude that Apiezon-W is a novel and ideal choice, which is easy to operate and has strong protective capability.

\section{Results and Discussion}

Figure 8 is the cross-section SEM image of the $2 \mu \mathrm{m}$ thick $\mathrm{ZnO}$ film. This figure shows that the $\mathrm{ZnO}$ columnar grains 


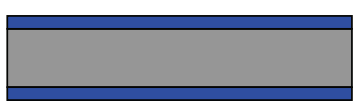

(a)

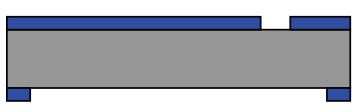

(b)

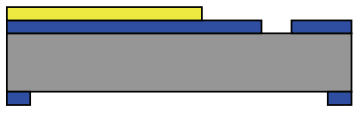

(c)

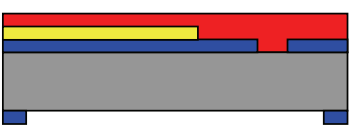

(d)

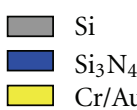

FIgURE 7: Fabrication processes of the sensor.

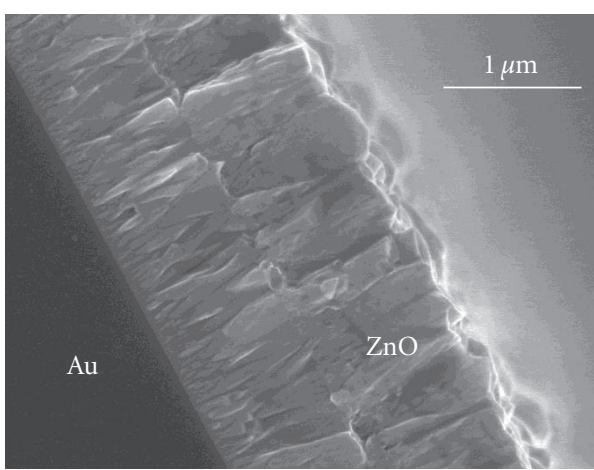

Figure 8: SEM image of the cross-section of the $\mathrm{ZnO}$ film.

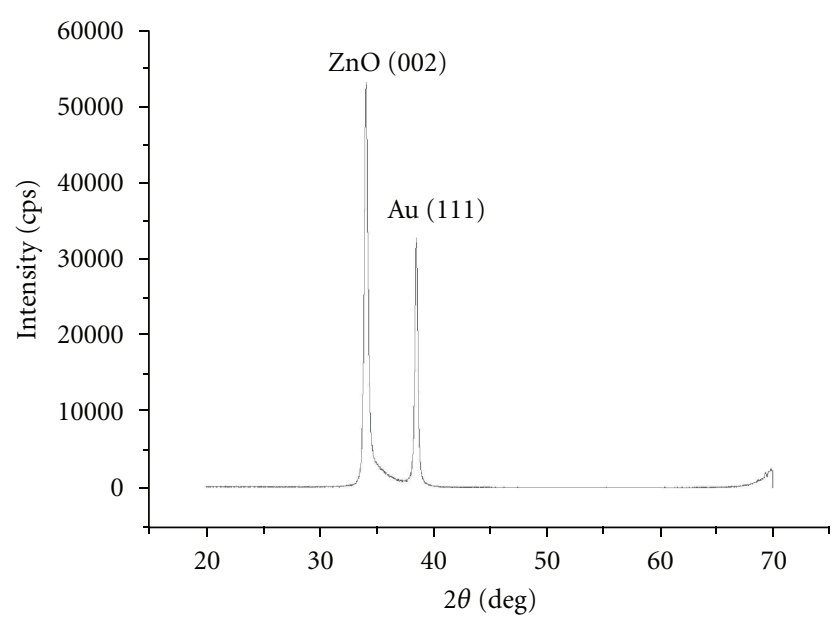

FIGURE 9: XRD pattern of the $\mathrm{ZnO}$ film on $\mathrm{Au}$.

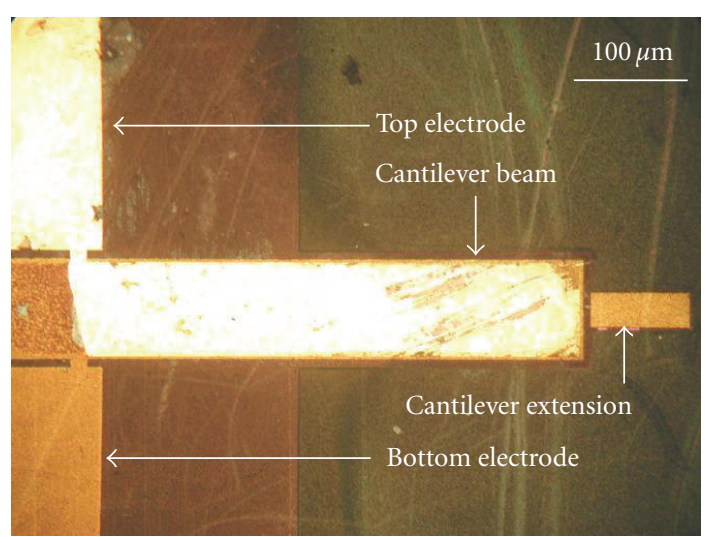

Figure 10: Fabricated piezoelectric $\mathrm{ZnO}$ cantilever.

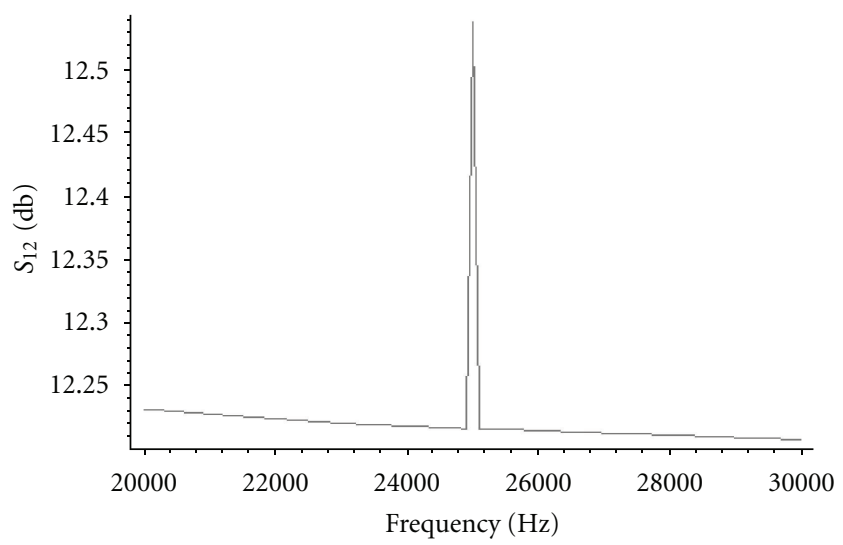

FIgURE 11: Frequency response of the piezoelectric $\mathrm{ZnO}$ cantilever sensor $\left(S_{12}\right.$ parameter $)$.

are clear and vertical to the substrate with a slight angle, indicating that the $\mathrm{ZnO}$ grains have good orientation. The $c$-axis orientation of the $\mathrm{ZnO}$ film is one of the most important factors of piezoelectric property, and the X-ray diffraction (XRD) pattern is used to investigate the $c$-axis properties. Figure 9 is the XRD pattern of the $\mathrm{ZnO}$ film with preferred (002) $c$-axis orientation. Figure 10 is the eventually fabricated piezoelectric $\mathrm{ZnO}$ cantilever sensor, which illustrates that the $\mathrm{ZnO}$ film is protected very well.

The fundamental resonant frequency of the piezoelectric $\mathrm{ZnO}$ cantilever sensor is measured by an Agilent E5100A network analyzer. From the frequency response curve shown in Figure 11, we can find that the fundamental resonant frequency of this piezoelectric $\mathrm{ZnO}$ cantilever sensor occurs at $24.60 \mathrm{kHz}$, very close to the calculation results and simulation results.

\section{Conclusions}

Using Rayleigh-Ritz method, the fundamental resonant frequency formula of T-shaped cantilevers is deduced for the first time, is validated by simulation results and experimental results, and can be widely used in design and optimization of 
T-shaped cantilevers. This formula illustrates that, comparing T-shaped cantilevers and rectangular cantilevers with the same dimensions and same materials, the former can lead to higher sensitivity. Then, a novel T-shaped piezoelectric $\mathrm{ZnO}$ cantilever sensor is designed and successfully fabricated by MEMS technique and finally tested by a network analyzer. The key step is protecting the $\mathrm{ZnO}$ film from $\mathrm{KOH}$ etching with a protective coating of black wax (Apiezon-W). This is one important technique that has shown considerable success. With this technique, many other delicate functional materials such as special ceramics, metals, polymers, and organic molecules will come into the use in the MEMS field. Experimental results show that this novel piezoelectric $\mathrm{ZnO}$ cantilever sensor has excellent dynamic response and can provide a new platform for chem/bio-sensing.

\section{References}

[1] B. C. Fagan, C. A. Tipple, Z. Xue, M. J. Sepaniak, and P. G. Datskos, "Modification of micro-cantilever sensors with sol-gels to enhance performance and immobilize chemically selective phases," Talanta, vol. 53, no. 3, pp. 599-608, 2000.

[2] Y. Lee, G. Lim, and W. Moon, "A piezoelectric micro-cantilever bio-sensor using the mass-micro-balancing technique with self-excitation," Microsystem Technologies, vol. 13, no. 5-6, pp. 563-567, 2007.

[3] Z. Cao, J. Zhang, and H. Kuwano, "Design and characterization of miniature piezoelectric generators with low resonant frequency," Sensors and Actuators A, vol. 179, pp. 178-184, 2012.

[4] P. K. Panda, "Review: environmental friendly lead-free piezoelectric materials," Journal of Materials Science, vol. 44, no. 19, pp. 5049-5062, 2009.

[5] K. Prashanthi, M. Naresh, V. Seena, T. Thundat, and V. Ramgopal Rao, "A novel photoplastic piezoelectric nanocomposite for MEMS applications," Journal of Microelectromechanical Systems, vol. 21, no. 2, Article ID 6118300, pp. 259-261, 2012.

[6] W. Zhou, A. Khaliq, Y. Tang, H. Ji, and R. R. Selmic, "Simulation and design of piezoelectric microcantilever chemical sensors," Sensors and Actuators A, vol. 125, no. 1, pp. 69-75, 2005.

[7] T. Itoh and T. Suga, "Self-excited force-sensing microcantilevers with piezoelectric thin films for dynamic scanning force microscopy," Sensors and Actuators A, vol. 54, no. 1-3, pp. 477-481, 1996.

[8] C. Sudhir and V. S. Atul, "Preparation and characterization of piezoelectric films of $\mathrm{ZnO}$ and AlN by RF sputtering for RF MEMS applications," Key Engineering Materials, vol. 500, pp. 84-89, 2012.

[9] F. Lochon, L. Fadel, I. Dufour, D. Rebière, and J. Pistré, "Silicon made resonant microcantilever: dependence of the chemical sensing performances on the sensitive coating thickness," Materials Science and Engineering C, vol. 26, no. 2-3, pp. 348353, 2006.

[10] S. D. Senturia, Microsystem Design, Kluwer Academic, Boston, Mass, USA, 2001. 

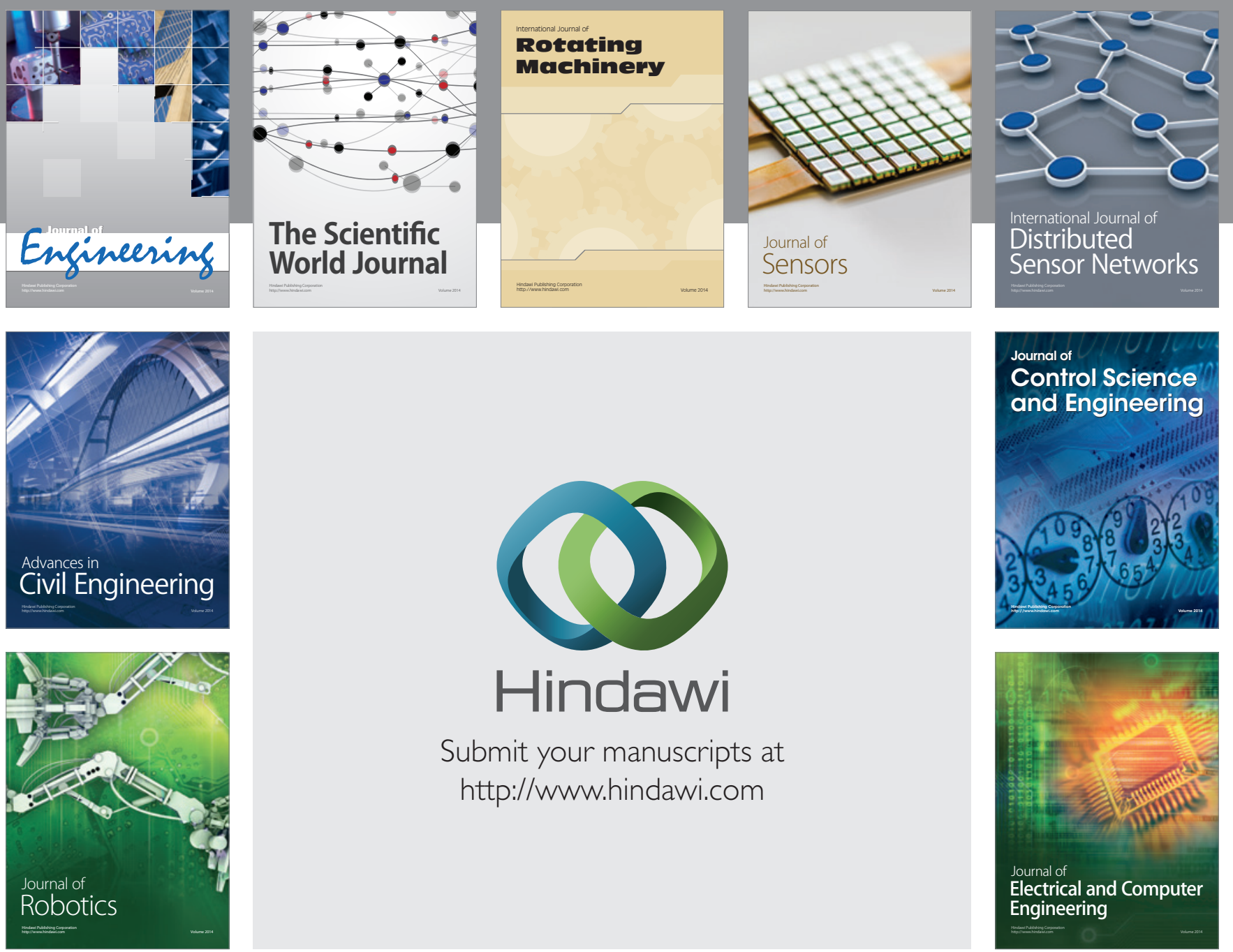

Submit your manuscripts at

http://www.hindawi.com
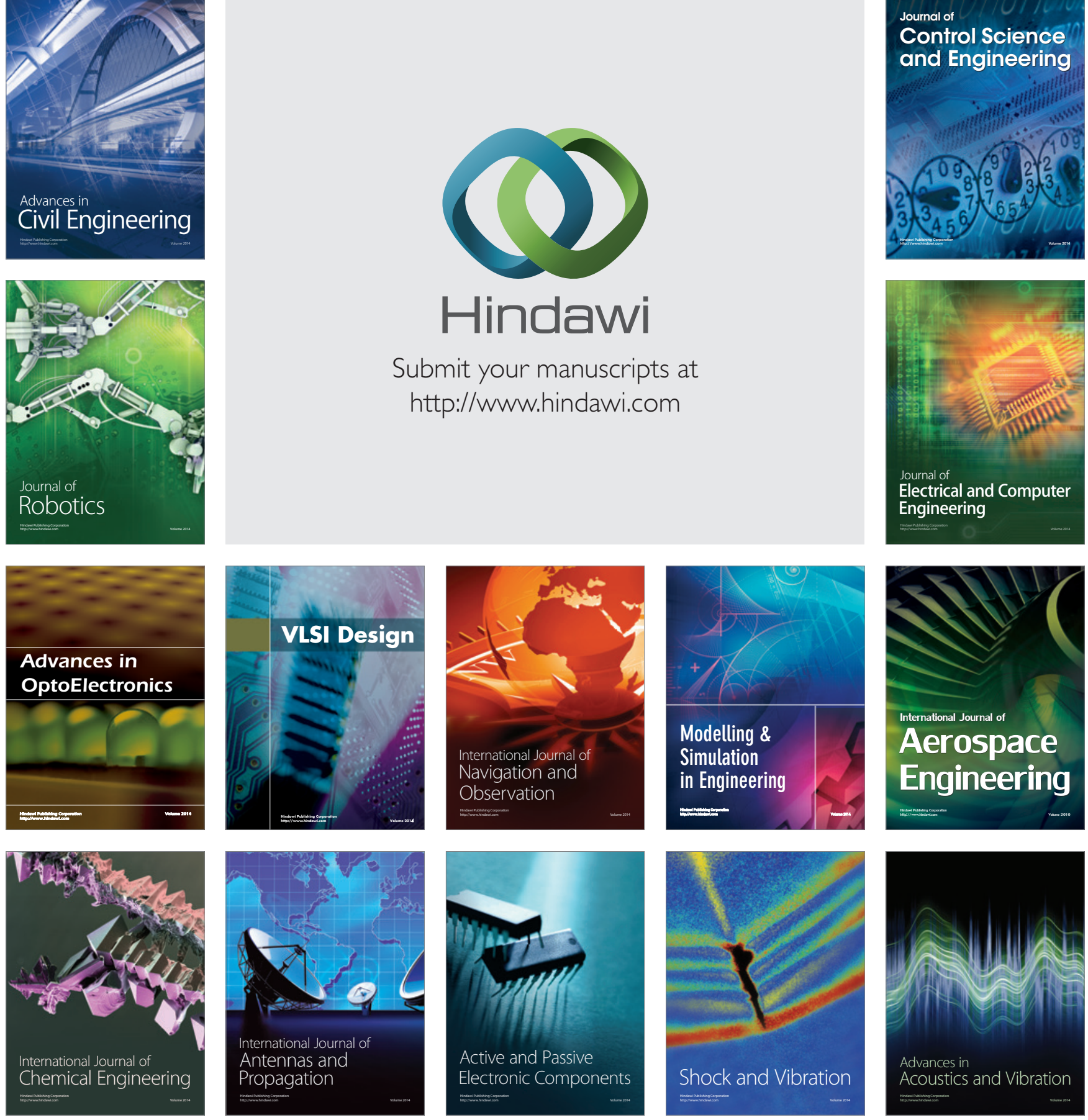